\title{
Prevalence of helicobacter pylori infection and associated factors among gastritis students in Jigjiga University, jigjiga, somali regional state of Ethiopia
}

\begin{abstract}
Background: H. pylori infection remains a major public health problem in Ethiopia. The aim of the present study is; therefore, to explore the prevalence of $H$. pylori infection and associated factors among gastritis Students in Jigjiga University, Jigjiga Town, Somali Regional State of Ethiopia.

Methods: Clinic-based cross-sectional study involving log book recorded data and pre-tested structured questionnaire, was conducted among gastritis students at Jigjiga University's clinic from May- June 2016.

Results: In the present study, a total of 145 gastritis students were recruited. The proportion of male and female gastritis students was $63.4 \%$ and $36.6 \%$ respectively. The prevalence of $H$. pylori infection among the study participants was $71.0 \%$ while its prevalence among male and female participants was $68.5 \%$ and $75.5 \%$ respectively. Meanwhile, most of the study participants developed khat chewing $(52.4 \%)$, alcohol drinking $(55.9 \%)$, and tobacco smoking (43.4\%) habits. The prevalence of $H$. pylori infection among chewers, drunker and smokers were $72.4 \%, 74.1 \%$ and $79.4 \%$ respectively. Tobacco smoking showed a trend of significant association with $H$. pylori infection ( $\mathrm{p}=0.053$ ). Consumption of protein rich food stuffs was also significantly associated with increased infection rate while khat chewing, coffee and tea consumption, and skipping meals were found to exacerbate $H$. pylori-related gastric complications $(\mathrm{p}<0.05)$. Importantly, lack of awareness on the transmission routes of $H$. pylori infection was strongly associated with increased prevalence of the disease among the study participants $(\mathrm{p}=0.025)$.
\end{abstract}

Conclusion: The prevalence of $H$. pylori infection was high among gastritis students in Jigjiga University. Thus, health education on the transmission routes and risk factors of $H$. pylori infection is underscored in this line to reduce the burden of the disease.

Keywords: prevalence, risk factors, helicobacter pylori, gastritis, jigjiga university, ethiopia
Volume 3 Issue 3 - 2016

\author{
Getachew Alebie, Desalegn Kaba \\ Department of Biology, Jigjiga University, Ethiopia
}

Correspondence: Getachew Alebie, Department of Biology, Jigjiga University, Jigjiga, PO Box- 1020, Ethiopia, Tel +251913014452, Email gechalebie@gmail.com

Received: November 13, 2016 | Published: December 09, 2016
Abbreviations: CI, confidence interval; OR, odds ratio; $\mathrm{IgG}$, IgM, IgA, immunoglobulin G,M,A

\section{Introduction}

Helicobacter pylori (H. pylori), deemed an etiology of gastritis and gastritis associated diseases, peptic ulcer, gastric adenocarcinoma and primary gastric lymphoma, ${ }^{1,2}$ is a major public health problems both in developed and developing countries, with high burden in economically poor countries related to poor sanitary conditions. Epidemiologic studies have been indicated that about $50 \%$ of adults in developed countries and $90 \%$ of adults in developing countries are positive to H. pylori. ${ }^{3}$

Infection with this organism is relatively common in Africa and it is the main cause of at least $90 \%$ of duodenal ulcers and $70 \%$ of gastric ulcers. Studies conducted in various parts of this continent have revealed high seroprevalence of infection (61-100\%) which varied in different countries and across different racial groups within each country. ${ }^{4,5}$ Childhood acquisition is the rule with more than $50 \%$ of all children in Africa being infected by the age of 10 years. ${ }^{6}$

Despite the exact mode of transmission of $H$. pylori is yet to be elucidated, several lines of studies have been reported that person- to-person transmission by either the oral-oral or fecal-oral route is postulated. Another possible route of transmission might be through direct ingestion of the bacteria while drinking water contaminated with fecal matter. ${ }^{7}$ Wherein, socioeconomic factors, environmental factors, sociocultural practices and genetic predisposition may all contribute toward acquisition of $H$. pylori infection ${ }^{8}$ whereas poor self and environmental hygienic practices, and crowded living conditions, social status, ethnic groups, region, age, nutrition status, blood groups are among frequently reported factors for acquisition of $H$. pylori infection. ${ }^{4,9-12}$ In fact $H$. pylori infection had considerable impact in the development of gastric diseases, other factors including immunological response and lifestyle factors developed during adulthood such as smoking, khat chewing and alcohol consumption could also influenced on the pathogenesis of the disease. ${ }^{13}$

The epidemiology of $H$. pylori in Ethiopia shows remarkable variations with regions, study population, ethnic groups and sociocultural practices. ${ }^{9,14,15}$ The prevalence of $H$. pylori infection in Ethiopia was in the range of $56-70 \% .{ }^{16}$ However, recent population and hospital based studies in different parts of the country showed that the prevalence ranged $62.5-91 \% .{ }^{17}$ Chronic H. pylori infection also deemed for entailed chronic gastritis with the overall prevalence of the infection in adult dyspeptic patients varied between 69 and $91 \%{ }^{4}$ 
Based on personal observation and information obtained from students, gastritis posed considerable health problems among Jigjiga University students, Jigjiga Town. However, research conducted to determine the prevalence of $H$. pylori infection and associated factors is meager. Therefore, the present study is attempted to explore the prevalence of $H$. pylori infection and its associated factors among gastritis students in Jigjiga University, Jigjiga Town, Somali Regional State of Ethiopia.

\section{Methods}

\section{Study area}

The study was conducted at Jigjiga University's Clinic in Jigjiga town, Somali regional state of Ethiopia. The town is found $626 \mathrm{~km}$ east from the capital city, Addis Ababa. The clinic offers health services to the university students.

\section{Study design}

Clinic-based cross-sectional study using log book recorded data of 145 patients and pre-tested structured questionnaire was conducted at Jigjiga University Clinic from May- June 2016 to determine the prevalence of $H$. pylori and associated risk factorsamong gastritis students who visited the clinic and who were attending their study during the study period.

\section{Study population}

The study population constitutes gastritis students who were attending their study in the regular bases at Jigjiga University during the survey period and who visited the clinic.

\section{Data collection}

Prior to screen gastritis patients; the recorded clinical data of all regular students who visited the clinic were reviewed. Thereafter, students who had gastritis, and who were at study during the survey period were screened. In the meantime, clinical data of $H$. pylori positive and $H$. pylori negative gastritis students were recorded.

Copies of pre-tested structured questionnaire were distributed for 145 respondents and information on demographic characters such as age, sex; life styles such as alcohol consumption, khat chewing, tobacco smoking; hygienic practices, dietary conditions and health status and awareness related to $H$. pylori infection were gathered.

\section{Laboratory method}

The clinic laboratory was employed a serological method to detect antibodies for $H$. pylori from serum or plasma. Rapid test device (dBest H. pylori test strip, Ameritech USA) was used to detect anti H. pylori antibodies of all isotypes (IgG, $\operatorname{IgM}$, and $\operatorname{IgA}$ ) against these bacteria. Appearance of color band on the device on both test line and control line was interpreted as positive whereas negative result was interpreted when color band is appeared only on the control line.

\section{Data analysis}

All data were entered into Statistical Software Packages for Social Science (SPSS, software version 22.0). Descriptive statistics was computed to determine frequency and percentage. Chi-square statistic was used to determine the associations between demographic characteristics, life styles and related factors and $H$. pylori positivity among the study subjects. Logistic regression was used to examine the possible transmission factors. An adjusted odds ratio was obtained using a confidence interval (CI) of $95 \%$. For all included studies, $P$ value $<0.05$ was regarded as statistically significant.

Ethical approval was obtained from Jigjiga University research committee and the university's clinic before conducting the study. Prior to consent for participation, all relevant information about the study was briefly explained to study subjects and assurance was made to all participants on the confidentiality of the results of study. Finally, verbal consent was obtained from the study participants.

\section{Results}

\section{Prevalence of $H$. pylori infection and life style habits}

In the present study, a total of 145 study participants were recruited, of whom $63.4 \%$ were males and $36.6 \%$ were females. As the study participants were degree of bachelor students, their age was ranged 18-28 years old. The prevalence of $H$. pylori infectionamong the study participants was $71.0 \%$. The prevalence among male was $68.5 \%$ and among female was $75.5 \%$. However, gender was not significantly associated with $H$. pylori infection $(\mathrm{X} 2=0.799 ; \mathrm{p}=0.371)$ (Table 1$)$.

Table I Distribution and association of $H$. pylori infection by demographic and life style factors among the study participants

\begin{tabular}{|c|c|c|c|c|c|c|}
\hline Variables & & $\mathbf{N}(\%)$ & H. pylori positive $\mathbf{N}(\%)$ & H. pylori negative $\mathbf{N}(\%)$ & $\mathbf{X} 2$ & p-Value \\
\hline \multirow{2}{*}{ Gender } & Male & $92(63.4)$ & $63(68.5)$ & $29(31.5)$ & 0.799 & 0.371 \\
\hline & Female & $53(36.6)$ & $40(75.5)$ & $13(24.5)$ & & \\
\hline \multirow{2}{*}{ Khat chewing } & Yes & $76(52.4)$ & $55(72.4)$ & $2 I(27.6)$ & 0.138 & 0.71 \\
\hline & No & $69(47.6)$ & $48(69.6)$ & $2 I(30.4)$ & & \\
\hline \multirow{2}{*}{ Alcohol drinking } & Yes & $8 I(55.9)$ & $60(74.1)$ & $2 \mathrm{I}(25.9)$ & 0.824 & 0.364 \\
\hline & No & $64(44.1)$ & $43(67.2)$ & $2 I(32.8)$ & & \\
\hline \multirow{2}{*}{ Tobacco smoking } & Yes & $63(43.4)$ & $50(79.4)$ & $13(20.6)$ & 3.757 & 0.053 \\
\hline & No & $82(56.6)$ & $53(64.6)$ & $29(35.4)$ & & \\
\hline
\end{tabular}

Most of the study participants had the habit of khat chewing (52.4\%), alcohol drinking (55.9\%), and tobacco smoking (43.4\%). The prevalence of $H$. pylori among chewers, drunker and smokers were $72.4 \%, 74.1 \%$ and $79.4 \%$ respectively (Table 1 ). Moreover, $47.3 \%, 64.2 \%$ and $73.0 \%$ of the study participants were experiencing khat chewing, alcohol drinking and tobacco smoking in the university respectively. The prevalence of $H$. pylori among these study participants were $72.2 \%, 78.8 \%$ and $78.3 \%$ respectively. Likewise, Majority $(73.1 \%)$ of the study participants were developed gastritis associated symptoms in the university while the prevalence of $H$. pylori in these groups of participants was $72.6 \%$ (data are not shown in the table). The aforementioned habits and duration of experience 
didn't show significant association with $H$. pylori infection $(\mathrm{P}>0.05)$. However, smoking generally showed a trend of significant association with $H$. pylori infection $(\mathrm{X} 2=3.757 ; \mathrm{p}=0.053)$ (Table 1$)$.

\section{Relationships between $H$. pylori infection and dietary} factors

As depicted in Table 2, the associations between ingestion of various food items, including raw vegetables, protein, carbohydrate and fat and oil rich food stuffs, and H. pylori infection were investigated. Consequently, ingestions of protein rich food stuffs, including meat, chick peas, beans, and lentil were significantly associated with this infection $(\mathrm{X} 2=4.828 ; \mathrm{p}=0.028)$. Indeed, the prevalence of $\mathrm{H}$. pylori infection was higher among participants who were ingesting raw vegetables, carbohydrate and, fat and oil rich food stuffs.

Table 2 The association between $H$. pylori infection and dietary factors

\begin{tabular}{lllllll}
\hline Food item & & N (\%) & Positive N (\%) & Negative N (\%) & X2 & P-Value \\
\hline \multirow{2}{*}{ Raw vegetable } & Yes & $16(11.0)$ & $14(87.5)$ & $2(12.5)$ & 2.37 & 0.124 \\
& No & $129(89.0)$ & $89(69.0)$ & $40(31.0)$ & & \\
\multirow{2}{*}{ Protein } & Yes & $15(10.3)$ & $7(46.7)$ & $8(53.3)$ & 4.828 & 0.028 \\
& No & $15(10.3)$ & $96(73.8)$ & $34(26.2)$ & & \\
Carbohydrate & Yes & $41(28.3)$ & $30(73.2)$ & $11(26.8)$ & 0.127 & 0.722 \\
& No & $104(71.7)$ & $73(70.2)$ & $31(29.8)$ & & \\
Fat and oil & Yes & $55(37.9)$ & $38(69.1)$ & $17(30.9)$ & 0.163 & 0.687 \\
& No & $90(62.1)$ & $65(72.2)$ & $25(27.8)$ & & \\
\multirow{2}{*}{ None } & Yes & $17(11.7)$ & $13(76.5)$ & $4(23.5)$ & 0.277 & 0.599 \\
& No & $129(88.3)$ & $91(70.3)$ & $38(29.7)$ & & \\
\hline
\end{tabular}

H.pylori infection and perceived symptom's aggravating factors

The present study highlighted that khat chewing, coffee and tea consumptions as well as skipping meal were found to significantly

worsen H. pylori positive gastritis $(\mathrm{p}<0.05)$ (Table 3). Despite no significant association observed, life style factors such as smoking, drinking, hunger, stress and anger, ingestions of spicy foods and drugs were found to aggravate symptoms of $H$. pylori gastritis than $H$. pylori negative gastritis.

Table 3 Distribution of some possible factors aggravating $H$. pylori positive gastritis among the study participants

\begin{tabular}{|c|c|c|c|c|c|c|}
\hline Factor & & $\mathbf{N}(\%)$ & H. pylori positive $\mathbf{N}(\%)$ & H. pylori negative $\mathbf{N}(\%)$ & $\mathbf{X} 2$ & P-Value \\
\hline \multirow{2}{*}{ Tobacco smoking } & Yes & $10(6.9)$ & $8(80.0)$ & $2(20.0)$ & 0.42 & 0.517 \\
\hline & No & $135(93.1)$ & $95(70.4)$ & $40(29.7)$ & & \\
\hline \multirow{2}{*}{ Alcohol drinking } & Yes & $24(16.6)$ & $16(66.7)$ & $8(33.3)$ & 0.267 & 0.606 \\
\hline & No & $121(83.4)$ & $87(71.9)$ & $34(28.1)$ & & \\
\hline \multirow{2}{*}{ Khat chewing } & Yes & $7(4.8)$ & $2(28.6)$ & $5(71.4)$ & 6.446 & 0.011 \\
\hline & No & $138(95.2)$ & $101(73.2)$ & $37(26.8)$ & & \\
\hline \multirow{2}{*}{ Spicy foods } & Yes & $62(42.8)$ & $40(64.5)$ & $22(35.5)$ & 2.237 & 0.135 \\
\hline & No & $83(57.2)$ & 63(75.9) & $20(24.1)$ & & \\
\hline \multirow{2}{*}{ Hunger } & Yes & $48(33.1)$ & $37(77.1)$ & II(22.9) & 1.276 & 0.259 \\
\hline & No & $97(66.9)$ & $66(68.0)$ & $3 I(32.0)$ & & \\
\hline \multirow{2}{*}{ Stress \& anger } & Yes & $25(I 7.2)$ & $17(68.0)$ & $8(32.0)$ & 0.135 & 0.713 \\
\hline & No & $120(82.8)$ & $86(71.7)$ & $34(28.3)$ & & \\
\hline \multirow{2}{*}{ Drinking coffee } & Yes & $14(9.7)$ & $4(28.6)$ & $10(7 \mid .4)$ & 13.58 & 0 \\
\hline & No & $97(97.0)$ & $77(75.6)$ & $20(24.4)$ & & \\
\hline \multirow{2}{*}{ Tea drinking } & Yes & $9(6.2)$ & $3(33.3)$ & $6(66.7)$ & 6.629 & 0.01 \\
\hline & No & 136(93.8) & $100(73.5)$ & $36(26.5)$ & & \\
\hline \multirow{2}{*}{ Skipping meals } & Yes & $4(2.8)$ & $I(25.0)$ & $3(75.0)$ & 4.237 & 0.04 \\
\hline & No & $|4|(97.2)$ & $102(72.3)$ & $39(27.7)$ & & \\
\hline \multirow{2}{*}{ Drugs } & Yes & $5(3.5)$ & $2(40.0)$ & $3(60.0)$ & 2.424 & 0.119 \\
\hline & No & $140(96.6)$ & $101(72.1)$ & $39(27.9)$ & & \\
\hline
\end{tabular}




\section{Transmission factors of $\boldsymbol{H}$. pylori infection}

In this study, most of the study participants $(68.3 \%)$ were used latrines while the remaining (31.7\%) study participants were defecate their faces in the open fields. The prevalence of $H$. pylori infections in these groups were $66.6 \%$ and $76.1 \%$ respectively. Most of the study participants had hand washing habit after visiting latrine (72.4\%), had awareness on the transmission ways of $H$. pylori infection (59.3\%) while $48.3 \%$ of the study participants had H. pylori- related gastritis history in their families. The prevalence of $H$. pylori infections in the aforementioned groups were $71.4 \%, 76.7 \%$ and $70.0 \%$ respectively. However, lack of awareness on the transmission ways of $H$. pylori was significantly associated with the prevalence of the infection $(p=0.025)$. Furthermore, those who had not awareness about the transmission ways of $H$. pylori had 2.53 times higher odds of being infected with this bacterium than aware participants.

Table 4 Association of $H$. pylori infection with some possible transmission factors.

\begin{tabular}{|c|c|c|c|c|c|}
\hline Factors & & $\mathbf{N}(\%)$ & H. pylori positive $\mathbf{N}(\%)$ & OR (95\% Cl) & P-value \\
\hline \multirow[b]{2}{*}{ Habit of using latrine } & yes & $99(68.3)$ & $66(66.6)$ & $1.014(0.42-2.43)$ & 0.11 \\
\hline & no & $46(31.7)$ & $35(76.1)$ & & \\
\hline \multirow{2}{*}{ Hand washing after latrine } & yes & $105(72.4)$ & $75(7 I .4)$ & $1.28(0.55-2.97)$ & 0.564 \\
\hline & no & $40(27.6)$ & $26(65)$ & & \\
\hline \multirow{2}{*}{ Awareness on the transmission routes } & yes & $86(59.3)$ & $66(76.7)$ & $2.53(1.12-5.72)$ & 0.025 \\
\hline & no & $59(40.7)$ & $35(59.3)$ & & \\
\hline \multirow{2}{*}{ Family history } & yes & $70(48.3)$ & $49(70)$ & $0.98(0.45-2.11)$ & 0.954 \\
\hline & no & 75(5।.7) & $52(69.3)$ & & \\
\hline
\end{tabular}

\section{Discussion}

The overall prevalence of $H$. pylori infection among participants was $71.0 \%$, which is comparable with other findings reported in Ethiopia. ${ }^{18-20}$ Moreover, the role of sex to differentially put men at higher risk of infection compared to women was observed in many studies. ${ }^{12,21,22}$ Nonetheless, such trend contradicted the present and others study findings. ${ }^{9,20,23}$

Life style habits have been recognized as important risk factors for acquisitions of various infections, including $H$. pylori infection. In the present study, majority of the students were experienced khat chewing, tobacco smoking and alcohol drinking in the university. Accordingly, the prevalence of $H$. pylori infection was high among these students. In agreement with the present study finding, other studies in the country also revealed that such habits are becoming common practice of university students, and posed considerable health effects, including H. pylori related gastritis. ${ }^{24-26}$ Handful of epidemiologic studies that have been conducted so far report inconsistent results regarding the association of cigarettes smoking and its predisposition to $H$. pylori infection. Some of which suggested that $H$. pylori risk significantly rose with cigarette smoking ${ }^{12,27}$ while others contradicted such trend. ${ }^{28-30}$ In the present study, smoking showed a trend of significant association with $H$. pylori infection. But, further study involving large sample size is underscored to ascertain the observed association. Advanced molecular based studies have revealed that pathogenicity of $H$. pylori is predominantly influenced by smoking. H. pylori, in non-virulent state, are present in the oral and the gastric milieu in acid peptic disease patients and asymptomatic subjects. Meanwhile, smoking is implicated to promote virulent infection in individuals by inducing the expression of virulent genes, including cag A, E and T. ${ }^{31-33}$ These genes are the needle and syringe mechanism of $H$. pylori and play a pivotal role in the transformation of an ulcerated gastric lining into a malignant tumor. Hence, smoking might be a major risk factor entailed in modulating the susceptibility of an individual suffering with ulcers to $H$. pylori infection. Evidently, study on $H$. pylori positive asymptomatic and symptomatic subjects with acid peptic disease showed that the risk of virulent infection was escalated by smoking in both groups of individual. ${ }^{32}$

Various food stuffs, such as raw vegetables, protein, fat and oil rich foods were found to aggravate gastritis in $H$. pylori positive patients than $H$. pylori negative gastritis patients. ${ }^{34,35}$ However, the present study found that protein rich food stuffs were implicated to increase the risk of $H$. pylori infection and further worsen gastric complications. It has elucidated that $H$. pylori could survive in some animal products with reach source of protein, including meats and dairy products at temperature below $30^{\circ} \mathrm{C} .{ }^{36}$ This might possibly serve as an important source of infection. Moreover, such foods could serve as source of amino acid such as arginine, histadine, methionine for the growth of this bacterium in the stomach. On the contrary, studies have revealed that $H$. pylori activity could be suppressed via dietary methods. A 2009 Japanese study in Cancer Prevention Research found that eating as little as $70 \mathrm{~g}$ ( 2.5 ounces) of broccoli sprouts daily for two months reduces the number of colonies of this bacteria in the stomach by $40 \%$ in mice and humans. ${ }^{37}$

Moreover, khat chewing, coffee and tea consumptions as well as skipping meals were found to significantly associate with $H$. pylori related gastric complications. The presences of astringent tannis in khat capable of inducing inflammatory reactions may perhaps aggravate $H$. pylori related complications of the gastric mucosa. ${ }^{38}$ It is also reported that all gastritis symptoms were higher in khat chewers than non-chewers. ${ }^{39}$ Coffee is highly acidic and it can stimulate the hyper-secretion of gastric acids, and in turn speed up the process of gastric emptying. ${ }^{40,41}$ Thus, its direct effect on the gastrointestinal tract may further worsen H. pylori associated pathology. ${ }^{42}$ In addition, coffee drinking hyper stimulated and increased the levels of stress related hormones such as cortisol, adrenaline and norepinephrine, ${ }^{43-45}$ and this in turn could negatively influence the activity of the immune system pertaining to combat this bacterium. Skipping meals is also found to have significant role in such matter. ${ }^{46}$

Poor sanitary practices and lack of awareness on the transmission routes of $H$. pylori is among widely recognized risk factor for the 
acquisition of such infection and the expression of clinical disease. ${ }^{47}$ In the present study, majority of $H$. pylori positive students were defecate their faces in the open fields. This is an evident that the study populations were unaware of the menace caused by inadequate hygiene practices. Importantly, lack of awareness on the routes of transmission was strongly associated with increased rate of $H$. pylori infection. Awareness creation on the society about good personal hygiene and environmental sanitation is the first step towards the control of $H$. pylori infection. ${ }^{48}$ Hence, good personal and environmental hygienic practices are pertaining to decrease the probability of the bacteria to contaminate food and water sources. Barik et al., ${ }^{49}$ noted that overcrowded conditions entailing closer contacts between individuals sharing the same bed is important factor for the acquisition of such infection. Institutionalization, including higher institutions creates overcrowded conditions, and this could be one possible reason for the observed high prevalence of $H$. pylori infection among the study participants.

\section{Conclusion}

This study revealed that the prevalence of $H$. pylori infection was high among Jigjiga University's gastritis students. Life style habits, including alcohol drinking, khat chewing and tobacco smoking were mostly practiced by the study participants. On the other hand, H. pylori infection rate was higher in these groups of students. Some of which habits were also found to show strong association with increased risk of $H$. pylori infection. Beside of the aforementioned habits, poor personal and environmental hygienic practices, lack of awareness on the transmission routes of $H$. pylori infection deemed the main factors responsible for the observed high prevalence. Therefore, health education on the negative health impacts of khat chewing, tobacco smoking and alcohol drinking, the transmission routes of $H$. pylori infection and its prevention methods is underscored to minimize the burden of the disease.

\section{Acknowledgements}

The authors would like to forward their gratitude to the Jigjiga University's college of Natural and Computational Science for the provision of materials during this research work. The authors are also thankful to Jigjiga university clinic, Jigjiga town for their consent to use the recorded clinical data. Finally, the authors would like to appreciate the study participants for their consent to participate and provide necessary information for this study.

\section{Conflict of interest}

The author declares no conflict of interest.

\section{References}

1. Johannes G, Arnoud H, Ernst J. Pathogenesis of Helicobacter pylori Infection. J Clin Microbiol. 2006;19(3):449-490.

2. Nurgalieva Z, Malaty H, Graham D, et al. Helicobacter pylori infection in Kazakhstan: Effect of water source and household hygiene. Am J Trop M. 2002;67(2):201-206.

3. Sgouros SN, Bergele C. Clinical outcome of patients with H. pylori infection: the bug, the host or the environment. Postgrad Med J. 2006;82(967):338-342.

4. Asrat D, Nilsson I, Mengistu Y, et al. Prevalence of Helicobacter pylori infection among adult dyspeptic patients in Ethiopia. Ann Trop Med Parasitol. 2004;98(2):181-189.

5. Ndip RN, MacKay WG, Farthing MJG, et al. Culturing Helicobacter pylori from clinical specimens: Review of microbiologic methods. $J$ Pediatr Gastroenterol Nutr. 2003;36(5):616-622.
6. Segal I, Ally R, Mitchell H. Helicobacter pylori: an African perspective. QJ Med. 2001;94(10):561-565.

7. Brown LM. Helicobacter pylori: epidemiology and routes of transmission. Epidemiol Rev. 2000;2(2):283-297.

8. Megraud FB, Rabbe MP, Denis F, et al. Seroepidemiology of Campylobacter pylori infection in various populations. J Clin Microbiol. 1989;27(8):1870-1873.

9. Tadege T, Mengistu Y, Desta K, et al. Seroprevalence of Helicobacter pylori infection in and its relationship with $\mathrm{ABO}$ Blood groups. Ethiop $J$ Health Dev. 2005;19(1):55-60.

10. De Oliveira AG, Rocha D, Queiroz, MB, et al. prevalence of $H$. pylori infection in a population from the rural area of aracua, $\mathrm{MG}$, Brazil. Revista de Microbiol. 1999;30:59-61.

11. Imrie C, Rowland M, Billy B, et al. Is Helicobacter pylori Infection in childhood a risk factor for gastric cancer? Pediatri. 2001;107(2):373380 .

12. Kanbay M, Gur G, Arslan H, et al. The relationship of ABO blood group, age. Gender, smoking, and Helicobacter pylori infection. Dig Dis. 2005;50(7):1214-1217.

13. Ogihara AS, Kikuchi A, Kurosawa M, et al. Relationship between Helicobacter pylori infection and smoking and drinking habits. $J$ Gastroenterol Hepatol. 2000;15(3):271-276.

14. Desta K, Asrat D, Derbie F. Seroprevalence of Helicobacter pylori infection among health blood donors in Addis Ababa, Ethiopia. Can J Gastroenterol. 2007;21(8):501-506.

15. Feleke M, Afework K, Getahun M. Seroprevalence of $H$. pylori in dyspeptic patients and its relationship with HIV infection, ABO blood groupings and life style in GUH. World J Gastroenol. 2006;12(12):19571961.

16. Tsega E, Gebre W, Manley P, et al. Helicobacter pylori, gastritis and nonulcer dyspepsia in Ethiopian patients. Ethiop Med J. 1996;34(2):65-71.

17. Alemayehu A. Seroprevalence of Helicobacter pylori infection and its risk factors among adult patients with dyspepsia in Hawassa Teaching and Referral Hospital. Ethiopia: Addis Ababa University; 2011.

18. Desta K, Asrat D, Derbie F. Seroprevalence of Helicobactor pylori infection among health blood donors in Addis Ababa, Ethiopia. Can J Gastroenterol. 2007;21:501-506.

19. Kassa E, Tsega E, Gebre W. Comparison of diagnostic methods for detection of Helicobacter pylori. East Afr Med J. 1996;73(4):239-241.

20. Mathewos B, Moges B, Dagnew M. Seroprevalence and trend of Helicobacter pylori infection in Gondar University Hospital among dyspeptic patients, Gondar, northwest Ethiopia. BMC Res Notes. 2013;6(1):346

21. Valliani A, Khan F, Chagani B, et al. Factors Associated with Helicobacter pylori infection, results from a developing country-Pakistan. Asian Pac J Canc Prev. 2013;14(1):53-56.

22. Broutet N, Sarasqueta AM, Sakarovitch C, et al. Helicobacter pylori infection in patients consulting gastroenterologists in France:prevalence is linked to gender and region of residence. Eur J Gastroenterol Hepatol. 2001;13(6):677-684.

23. Seyda T, Derya C, Füsun A, et al. The relationship of Helicobacter pylori positivity with age, sex, and $\mathrm{ABO} /$ Rhesus blood groups in patients with gastrointestinal complaints in Turkey. Helicobacter. 2007;12(3):244 250 .

24. Kebede Y. Cigarette smoking and khat chewing among college students in North West Ethiopia. Ethiopian Journal of Health Development. 2002;16(1):9-17.

25. Gezahegn T, Andualem D, Mitiku TH. Substance Use and Associated Factors among University Students in Ethiopia: A Cross-Sectional Study. Journal of Addiction. 2014;1(1):1-8. 
26. Keno TS, Keskis W. Assessment of Causes, Prevalence and Consequences of Alcohol and Drug Abuse among Mekelle University, CSSL 2nd Year Students. American Journal of Applied Psychology. 2015;3(3):47-56.

27. Ozden AG, Bozday OM. Changes in the seroepidemiological Pattern of Helicobacter pylori infection over the last 10years in Turkey. Turk $J$ Gastroenterol. 2004;15(3):156-158.

28. Woodward MC, Morrison, McColl K. An investigation in to factors associated with Helicobacter pylori infection. J Clin Epidemiol. 2000;53(2):175-181.

29. Akin LS, Tezcan S, Hascelik G, et al. Seroprevalence and some correlates of Helicobacter pylori at adult ages in Gulveren Health District, Ankara, Turkey. Epidemiol Infect. 2004;132(5):847-856.

30. Camargo MC, Lazcano Ponce E, Torres J, et al. Determinants of Helicobacter pylori seroprevalence in Mexican adolescents. Helicobacter. 2004;9(2):106-114.

31. Ghosh P, Bodhankar SL. Application of polymerase chain reaction for determination of prevalence of Helicobacter pylori in salivary samples of asymptomatic subjects. Asian journal of Pharmaceutical and clinical research. 2011;4(3):21-24.

32. Ghosh P, Bodhankar SL. Association of Smoking, alcohol and NSAID use with expression of cag A and cagT genes of $H$. pylori in salivary samples of asymptomatic subjects. Asian Pac J Trop Biomed. 2012;1(1):479-484.

33. Ghosh P, Bodhankar SL. Determination of risk factors and transmission pathways of Helicobacter pylori in asymptomatic subjects in western India using polymerase chain reaction. Asian Pacific Journal of Tropical Diseases. 2012;2(1):12-17.

34. Ddine LC, Ddine CC, Rodrigues CC, et al. Factors associated with chronic gastritis in patients with presence or absence of $H$. pylori. Arq Bras Cir Dig. 2012;25(2):96-100.

35. Guha S. Foods to avoid during gastritis. 2015

36. West AP, Miller MR, Tompkins DS. Effect of physical environment on survival of Helicobacter pylori. J Clin Pathol. 1992;45(2):228-231.
37. Mehmood MA, Akram M, Afzal AS, et al. Helicobacter Pylori: An Introduction. 2010;1(3):1337.

38. Daisy A, Carlos A, Hildegardo C. Evaluation of constipation. Am Fam Physician. 2002;65(11):2283-2290.

39. Sikirov BA. Management of hemorrhoids: a new approach. Isr J Med Sci. 1987;23(4):284-286.

40. Coffey RJ, Go VL, Zinsmeister AR, et al. The acute effects of coffee and caffeine on human interdigestive exocrine pancreatic secretion. Pancreas. 1986;1(1):55-61.

41. Borger HW, Schafmayer A, Arnold R, et al. The influence of coffee and caffeine on gastrin and acid secretion in man. Deutsche medizinische Wochenschrift. 1976;101(12):455-457.

42. Naliboff BD, Mayer M, Fass R, et al. The effect of life stress on symptoms of heartburn. Psychosomatic Med. 2004;66(3):426-434.

43. Marotta RB, Floch MH. Diet and nutrition in ulcer disease. Med Clin North Am. 1991;75(4):967-979.

44. Robertson D, Frolich JC, Carr RK, et al. Effects of caffeine on plasma renin activity, catecholamines and blood pressure. $N$ Engl $\mathrm{J}$ Med. 1978;298(4):181-186.

45. Lane JD, Adcock RA, Williams RB, et al. Caffeine effects on cardiovascular and neuroendocrine responses to acute psychosocial stress and their relationship to level of habitual caffeine consumption. Psychosomatic Med. 1990;52(3):320-336.

46. Abu Farsakh NA. Risk factors for duodenal ulcer disease. Saudi Med J. 2002;23(2):168-172.

47. Linda MB. Helicobacter pylori: Epidemiology and routes of transmission. Epidemiol Rev. 2000;22(2):283-297.

48. Federal Republic of Nigeria. Legal notice on publication of 2006 census final results Official Gazette. 2009;96:B1-B42.

49. Salih BA. Helicobacter pylori Infection in Developing Countries: The Burden for How Long? Saudi J Gastroenterol. 2009;15(3):201-207. 